\title{
A civilização e a deterioração dos monumentos de pedra
}

\begin{abstract}
"Nunca anteriormente se deu maior apreço à conservação dos vestígios do passado. Nunca também se acumularam tantas causas da sua destruição. Esta situação paradoxal é particularmente verdadeira para os monumentos. Ameaçados e destruidos pela evolução das nossas necessidades e pela tranformação das nossas cidades e das nossas aldeias, são-no também pela poluição do ar e do solo, esse preço nefasto que nós pagamos, entre outros, pelo desenvolvimento da economia e aumento do nosso conforto.

Certamente, desde sempre, a natureza ameaça destruir a obra do homem. Os templos gregos são atacados desde a sua construção pelo ar salino do mar vizinho. $O$ sol desagrega lentamente os granitos dos templos do Egipto e a água dissolve pouco a pouco os calcários das igrejas de França. Transformada em gelo, faz estalar as pedras geladiças desde a sua colocação em obra. Mas a estas causas naturais, cuja ação é muitas vezes lenta e pouco perceptível, o homem da época industrial juntou agentes de destruição novos e temiveis. A sua intervenção é por vezes fulgurante e decisiva: à imagem do nosso tempo.

A sulfatação das pedras terá destruído em menos de duas gerações numerosas obras primas que vinte outras admiraram sob uma forma quase intacta. Ela terá aniquilado ou danificado em menos de meio século mais obras primas que as duas guerras mundiais."
\end{abstract}

Prof. Dr. R.M. Lemaire Colloques sur l'Altération des Pierres, Bruxelas, 1966-1967

\section{Introdução}

Estas palavras do Prof. Lemaire [1] são suficientemente eloquentes para dispensarem comentários sobre a importância dos agentes destrutivos das pedras dos monumentos, os quais na nossa época constituem uma ameaça crescente.

Iremos apenas mencionar a acção química de alguns de entre eles que decorrem das actividades dos homens ou ainda são consequência de más técnicas de conservação de monumentos.

\section{Acção da poluição atmosférica sobre as pedras}

A expansão dos centros urbanos, o seu trânsito cada vez mais intenso, as indústrias cada vez mais numerosas e mais potentes têm contribuído para um vertiginoso acréscimo da poluição atmosférica com consequências desastrosas para os monumentos de pedra. A fig. 1 mostra em esquema uma goteira da Catedral de Colónia, construída em grés de Schlaidorf em 1861, pelo qual pode ver-se que a zona atacada, reproduzida a preto, progride com uma velocidade cerca de 8 vezes superior à de há um século [2].

O grau de deterioração sofrido pela pedra está relacionado não só com a composição qualitativa e quantitativa dos agentes da poluição como com as características da própria pedra. Assim, a sua composição química (substâncias reactivas) e mineralógica (minerais susceptíveis de meteorização, ligação entre partículas, dimensðes dos grãos) e as suas propriedades físicas (porosidade, superfície específica, porometria) são pa- râmetros de que depende a sua susceptibilidade aos agentes agressivos. Compreende-se assim que o ataque e destruição da pedra resultem de uma interligação complexa de factores, de difícil análise.

Não é fácil estabelecer a composição da atmosfera pura, isto é, não poluída. Segundo Urone [3] os seus constituintes mais abundantes são o azoto $(78,09 \%)$, o oxigénio $(20,94 \%)$, o argon $(0,093 \%)$ e o dióxido de carbono $(0,032 \%)$. Outros componentes, em pequenas quantidades, existem ainda normalmente, podendo citar-se (expressos em p.p.m.) os seguintes: $\mathrm{Ne}(18), \mathrm{He}$ $(5,2) \mathrm{CH}_{4}(1,5), \mathrm{Kr}(1), \mathrm{N}_{2} \mathrm{O}(0,5), \mathrm{H}_{2}(0,5), \mathrm{Xe}(0,08)$, $\mathrm{O}_{3}(0,01-0,04)$.
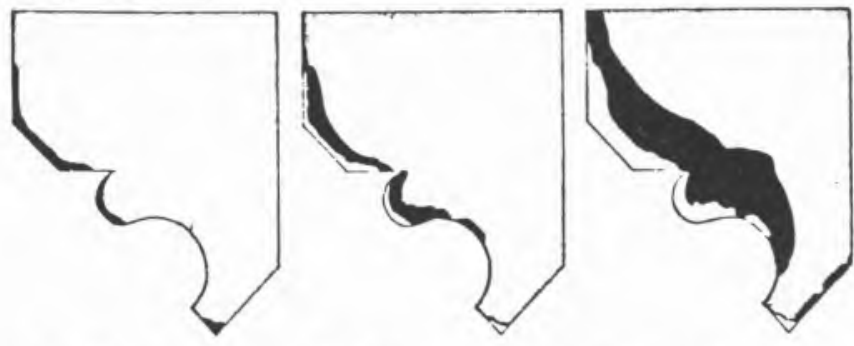

$$
\begin{aligned}
& \text { 186) } 1003.22 \text { anes } 1903.1919 .36 \text { anes } 1919.1972 .53 \text { anos }
\end{aligned}
$$

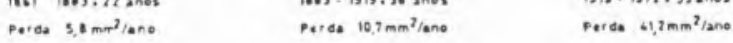

Catedral de Colsnia - Progresso da desintegração observada numa goteira (segundo [2]).

Existem também vestígios de muitos outros gases, tais como $\mathrm{SO}_{2}, \mathrm{CO}$, numerosos hidrocarbonetos, etc.

Muitos dos componentes considerados poluentes encontram-se já no ar puro, mas, na atmosfera poluida, a sua concentração pode estar consideravelmente aumentada por actividades humanas, particularmente nas áreas de densa população ou junto das grandes fontes de emissão.

Como se disse, os poluentes atmosféricos têm uma importante acção na deterioração das pedras; como, porém, muitos deles se encontram presentes simultaneamente é muito difícil, se não impossível, quantificar o efeito de cada um isoladamente.

Os poluentes com maior incidência na deterioração das pedras são os seguintes: compostos oxigenados do enxofre, dióxido de carbono, óxidos de azoto, ácido clorídrico e cloretos, ácido fluorídrico e fluoretos, ácido sulfidrico, ozono, amónia e poeiras.

$\mathrm{O}$ dioxido de enxofre é o poluente de acção mais deletéria, pois é o maior responsável pela formação de crostas, cujo componente principal è o sulfato de cálcio (frequentemente sob a forma de gesso, $\mathrm{CaSO}_{4}$, $2 \mathrm{H}_{2} \mathrm{O}$ ), (Figs. 2 e 3 ).

$\mathrm{O}$ ciclo do $\mathrm{SO}_{2}$ na atmosfera e os mecanismos da sua

\footnotetext{
a Laboratório Nacional de Engenharia Civil.
} 
acção sobre as pedras podem ser diversos e muito complexos.

Segundo Amoroso e Fassina [5] há três caminhos possíveis:

«(i) Deposição do $\mathrm{SO}_{2}$ a seco, que é um mecanismo lento mas contínuo.

(ii) Deposição húmida do $\mathrm{SO}_{2}$ seguindo os passos: (1) conversão em sulfato na fase gasosa; (2) assimilação do sulfato pelo aerosol existente; (3) deposição sobre a superfície.

(iii) Deposição húmida do $\mathrm{SO}_{2}$ seguindo os passos: (1) absorção em água por dissolução; (2) oxidação na fase aquosa do $\mathrm{SO}_{2}$ dissolvido; (3) deposição sobre a superfície.»

Não cabe porém na extensão deste artigo descrever as diferentes fases destes processos, cujas consequências são funestas especialmente para as pedras contendo carbonatos de cálcio ou magnésio. As chuvas ácidas são um fenomeno há bastante tempo observado na Europa e também nos Estados Unidos e Canadá.

$\mathrm{O}$ dióxido de carbono é, como se referiu, um constituinte normal da atmosfera e em condiçð̃es naturais a sua proporção mantendo-se sensivelmente constante, pois embora esteja sempre a ser produzido pela respiração dos homens e dos animais, o equilibrio é restabelecido pelas plantas através da fotossíntese. Porém, quando a sua concentração aumenta muito, nas atmosferas urbanas ou industriais, pode ser considerado como um poluente.

Com efeito, $\mathrm{O} \mathrm{CO}_{2}$ dissolve-se nas águas das chuvas segundo a reacção:

$\mathrm{CO}_{2}+\mathrm{H}_{2} \mathrm{O} \rightarrow\left(\mathrm{CO}_{2} \cdot \mathrm{H}_{2} \mathrm{O}\right)$

gás líquido líquido

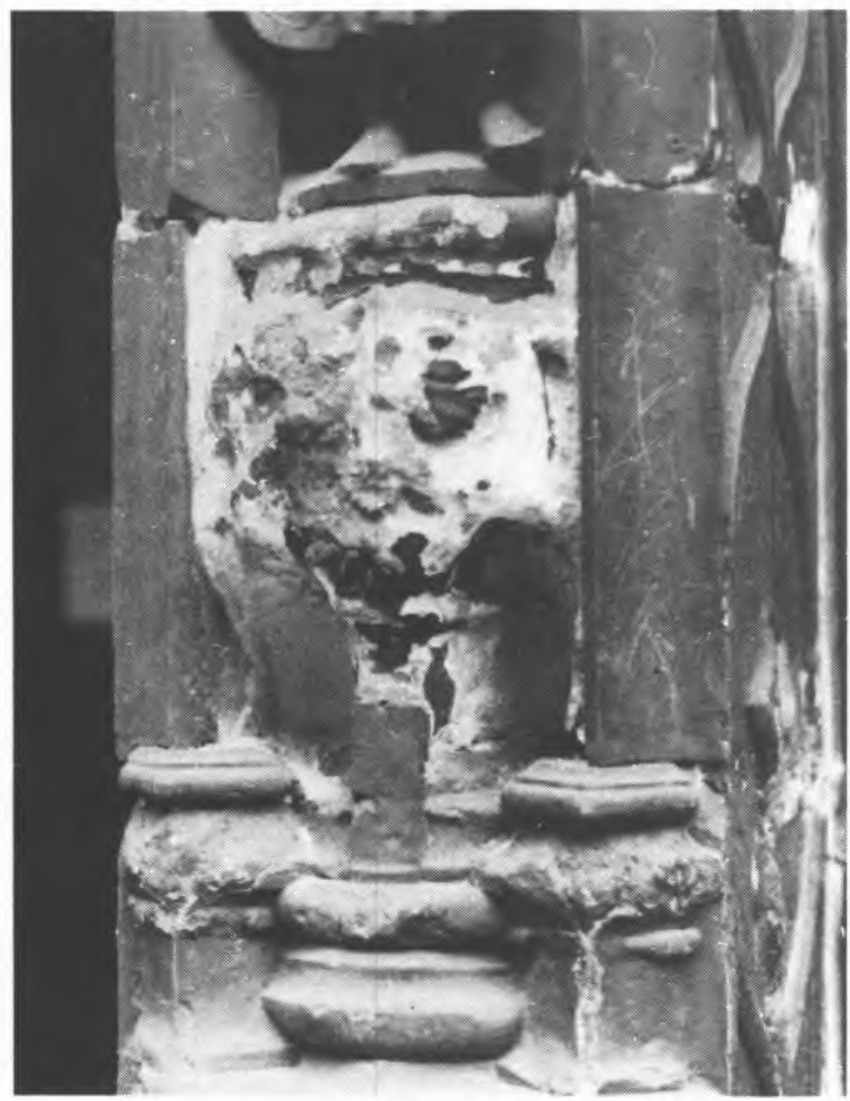

Fig. 2

Igreja da Conceição Velha - Pilar central do pórtico. Bloco muito alterado com o relevo superficial já destruido [4]

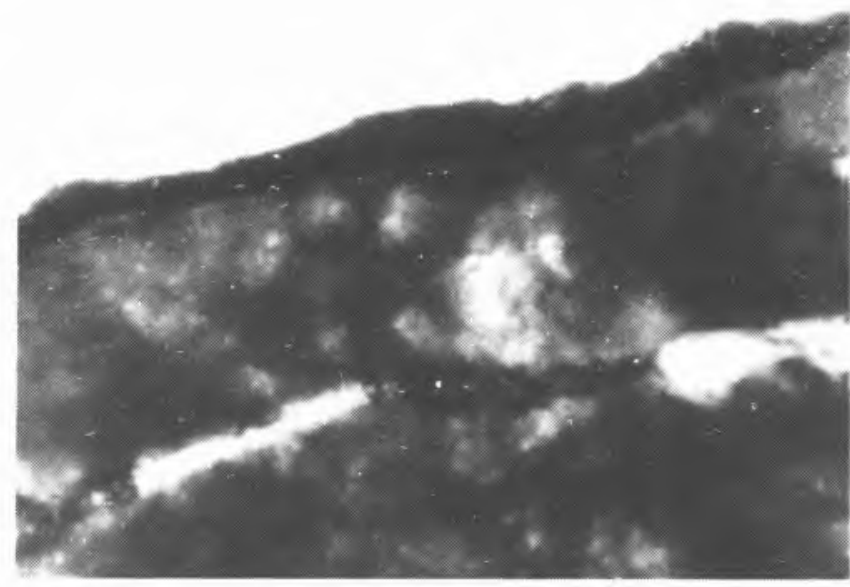

Fig. 3

Microfotografia de uma crosta (Nicois II; ampliação 175 ×) [4].

Ora o carbonato de cálcio, que é pouco solúvel em água pura, dissolve-se em quantidade apreciável quando a água contém dióxido de carbono, dando lugar a hidrogenocarbonato de cálcio:

$\mathrm{CaCO}_{3}+\mathrm{CO}_{2} \cdot \mathrm{H}_{2} \mathrm{O} \leftrightarrows \mathrm{Ca}\left(\mathrm{HCO}_{3}\right)_{2}$

Assim a superfície dos calcários, ou das rochas contendo carbonato de cálcio, vai sendo atacada e erodida quimicamente. Parte do hidrogenocarbonato de cálcio formado é levada pelas águas das chuvas, mas parte permanece nos poros da pedra e, quando a água se evapora, é depositado de novo sob a forma de carbonato de cálcio, por vezes em pontos diferentes daqueles em que se deu a sua dissolução, acentuando-se a erosão diferencial:

\section{$\mathrm{Ca}\left(\mathrm{HCO}_{3}\right)_{2} \rightarrow \mathrm{CaCO}_{3}+\mathrm{CO}_{2} \mathrm{H}_{2} \mathrm{O}$}

Os grés calcários em que os grãos são cimentados por carbonato de cálcio são também rapidamente atacados, dando-se a destruição do cimento e a desagregação da rocha.

O carbonato de magnésio sofre idêntico ataque ao do carbonato de cálcio, pelo que as dolomites ou os calcários magnesianos estão também sujeitos a este mecanismo de solubilização.

Os bxidos de azoto têm também um papel relevante na deterioração dos calcários devido à sua transformação em ácido nítrico, dando lugar à formação de nitrato de cálcio que é muito solúvel e normalmente é lavado pelas chuvas, sendo por isso muito difícil quantificar a sua acção.

Podem também desempenhar um papel na oxidação do dióxido de enxofre:

$\mathrm{NO}_{2}+\mathrm{SO}_{2} \rightarrow \mathrm{NO}+\mathrm{SO}_{3}$

$\mathrm{NO}_{3}+\mathrm{SO}_{2} \rightarrow \mathrm{NO}_{2}+\mathrm{SO}_{3}$

$\mathrm{N}_{2} \mathrm{O}_{5}+\mathrm{SO}_{2} \rightarrow \mathrm{N}_{2} \mathrm{O}_{4}+\mathrm{SO}_{3}$

O ácido clorídrico reage com o carbonato de cálcio transformando-o em cloreto de cálcio. Este, tal como os nitratos, é muito solúvel e a sua acção sobre as pedras é muito difícil de avaliar.

O ácido fluorídrico tem efeitos não só sobre as pedras calcárias como também sobre as siliciosas. Embora seja pouco comum pode ocorrer nas zonas industriais. $\mathrm{O}$ ácido sulfídrico, presente em baixas concentraçðes, é um poluente cuja quantificação tem sido difícil, mas pensa-se que poderá ter também intervenção na formação do ácido sulfídrico por intermédio de oxidação biologica pelas tiobactérias. 
O ozono é um oxidante mais activo do que o oxigénio e é-lhe atribuído um papel importante no processo de oxidação do $\mathrm{SO}_{2}$.

A amónia é o único poluente básico que afecta as pedras, formando sais de amónio no ar, que penetram nas microfissuras e, cristalizando, dão lugar a deterioraçōes. Também lhe é atribuído um papel na oxidação por via húmida do $\mathrm{SO}_{2}$, por elevar o $\mathrm{pH}$ para a gama de 4-5 em que a oxidação do $\mathrm{SO}_{2}$ pelo $\mathrm{O}_{2}$ é mais fácil. As poeiras têm uma composição muito complexa e, além de contribuirem, pela sua deposição sobre a superfície da pedra, para a sujarem prejudicando assim o seu aspecto estético, criam também condiçðes ideais para os processos de oxidação catalizados pelas partículas de carbono e de outros metais presentes no pó (Fig. 4).

Intervêm ainda noutros processos tais como: formação de núvens e precipitação, radiaçðes atmosféricas, influência em reacçð̄es químicas (nomeadamente na oxidação do $\mathrm{SO}_{2}$ ).

A avaliação da acção da poluição sobre as pedras necessita ainda de muita investigação conduzida quer em laboratório quer "in situ», e tem sido objecto de estudos a nivel internacional.

Assim, por exemplo, no âmbito da OTAN, promovido pelo "Committee on the Challenges of Modern Society", foi realizado um estudo piloto relacionando a poluição atmosférica com os seus efeitos sobre a pedra, tendo em vista a conservação e a restauração de monumentos [6].

Este estudo, conduzido pela República Federal da Alemanha, incidiu sobre dois tipos de pedra muito frequentes nos monumentos daquele país: um calcário (Krensheim Muschelkalk) e um grés (Baumberg sandstone). Colocaram-se provetes em 27 locais nos quais foram simultaneamente determinados alguns dos componentes da poluição com maior agressividade (compostos oxigenados do enxofre, cloretos, fluoretos e óxidos de azoto) e os seus efeitos sobre os provetes expostos; 25 dos locais de exposição situavam-se na Europa (R.F.A., Inglaterra, Holanda, Itália, Noruega, Suécia, França e Grécia) e 2 nos Estados Unidos.

Mais do que a concentração momentânea no ar de um determinado agente agressivo importa a quantidade que é absorvida por unidade de superfície na unidade de tempo.

Esta determinação foi feita pelo métodc IRMA (Immissions - Raten - M e SS - Apparatur) [7], que

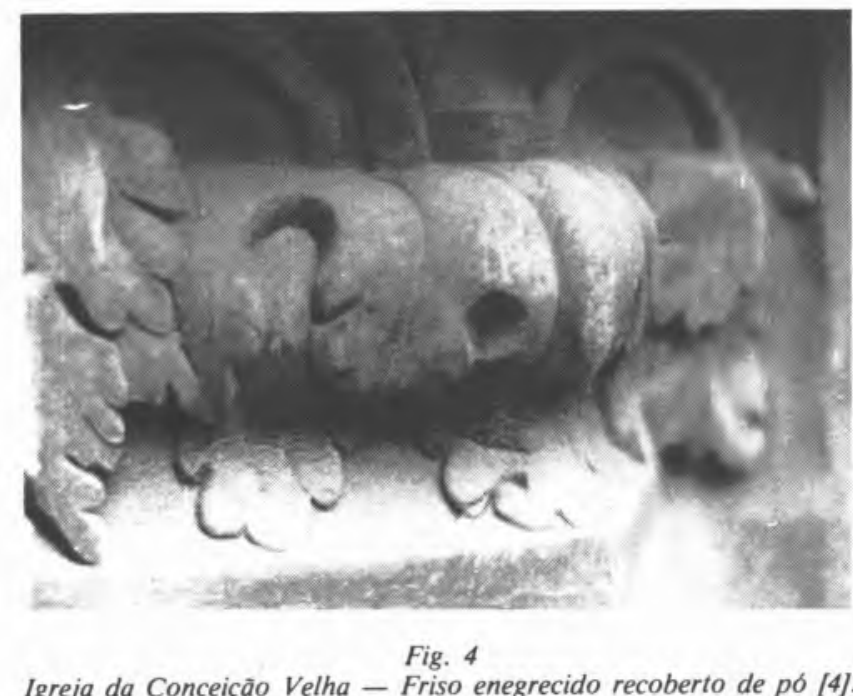

utiliza um aparelho baseado na reacção dos poluentes, que se pretende determinar, com um líquido absorvente adequado que escorre na forma de um filme contínuo (constituindo a superfície de medida) sobre uma manga cilíndrica que se encontra saturada. O líquido é continuamente reciclado por bombagem. Os produtos de reacção foram analisados periodicamente (períodos de 14 dias) e expressos em mg.m $\mathrm{m}^{-2} \cdot \mathrm{d}^{-1}$.

Paralelamente estes valores foram comparados com o teor em poluentes dos provetes colocados nos mesmos locais (uma série exposta às intempéries e outra abrigada da chuva).

Este estudo, entre outras conclusðes, evidenciou uma correlação entre os compostos oxigenados do enxofre presentes na atmosfera e a acumulação de poluentes sobre a pedra natural. Mostrou também que a corrosão do material pétreo depende de factores da dinâmica dos fluidos (velocidade média do gás, difusão, tempo de permanência) e das propriedades do material. Outros estudos à escala internacional visando a «determinação do impacto da poluição atmosférica (compostos do enxofre) sobre as pedras em obra" estão a ser conduzidos pelo Prof. Furlan da "École Polytechnique Fédérale de Lausanne", nos quais Portugal também toma parte por intermédio do Laboratório Nacional de Engenharia Civil.

$\mathrm{Na}$ fig. 5 pode ver-se um suporte contendo provetes de pedra exposto num dos janeløes da Igreja da Conceição Velha, em Lisboa.

Nestes provetes têm vindo a ser analisados os compostos de enxofre depositados durante determinados períodos de tempo.

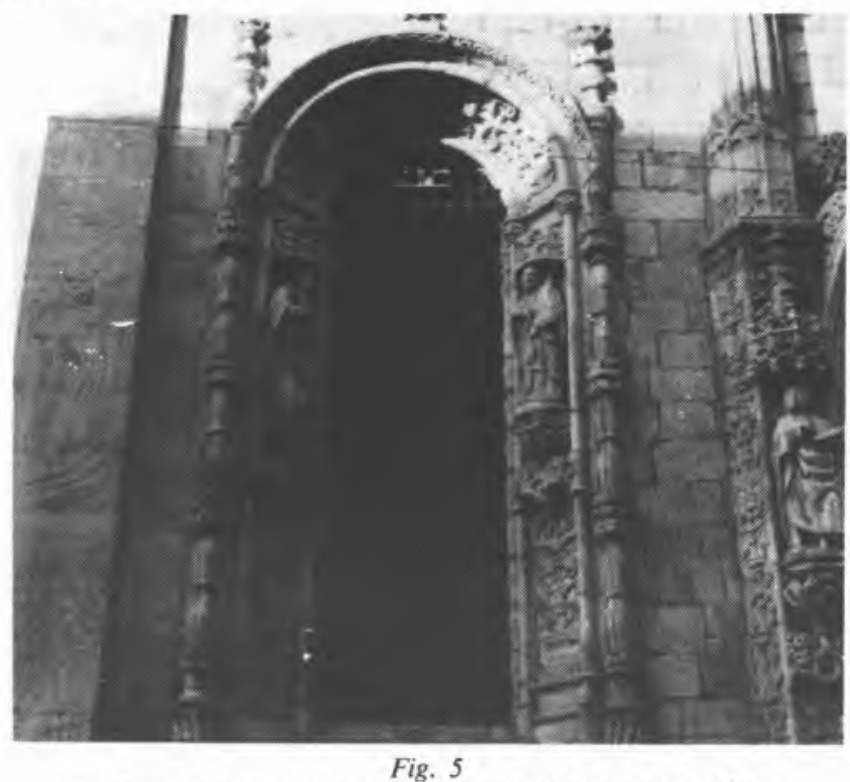

Provetes de pedra expostos na Igreja da Conceição Velha.

\section{Os metais e a deterioração das pedras}

Os metais como o chumbo, o estanho, o cobre, e suas ligas, têm sido utilizados na construção desde tempos imemoriais: tubos, coberturas, "gatos», chumbadouros, caleiras, etc.

Estes metais são os que mais facilmente se extraem dos seus minérios e de um modo geral comportaram-se bem perante a acção dos poluentes naturais atrás mencionados que produzem sobre eles uma película compacta e aderente que os protege de acção ulterior. Esta película é geralmente constituída por óxidos, sendo, no caso do chumbo, praticamente de carbonato básico: 
$\mathrm{Pb}+\mathrm{CO}_{2}+\mathrm{H}_{2} \mathrm{O} \rightarrow \mathrm{Pb}_{2}(\mathrm{OH})_{2} \mathrm{CO}_{3}$

As camadas referidas podem não ser protectoras, quando existam cloretos, pois estes, provocam a sua rotura seguindo-se corrosão acentuada.

Actualmente, devido aos poluentes industriais, os metais, tal como as pedras, comportam-se pior, com menor relevância para o chumbo, dada a grande insolubilidade do sulfato de chumbo.

Como podem os metais deteriorar a pedra?

Evidentemente que se tratará de uma deterioração fisica, pois os metais não a atacam quimicamente.

Um processo de deterioração será a formação de manchas coradas se os produtos de corrosão o forem, como é o caso do cobre e do ferro. Assim uma estátua de cobre ou bronze pode originar manchas verdes nas pedras do pedestal que a suporta. Note-se: é apenas uma alteração do aspecto, porque os produtos de corrosão dos metais não provocam por si só a deterioração química das pedras.

Os grandes problemas surgiram quando se começou a usar nas restauraçðes o ferro ou o aço, nomeadamente em gatos ou chumbadouros. O desaire que teve maior repercussão foi a restauração da Acrópole de Atenas [9] no primeiro quartel do séc. XX, na qual se utilizaram, não só elementos estruturais como vigas e outros, mas também elementos de união, gatos e chumbadouros, de aço. Passadas algumas dezenas de anos várias pedras apresentavam fissuras profundas. Os gatos, por exemplo, provocaram em alguns casos o destacamento de fragmentos de mármore compreendido entre os pontos de inserção.

Esta deterioração deveu-se à corrosão do aço pois os seus produtos de corrosão não produzem camadas protectoras, o que se explica seguidamente.

A corrosão do aço, como a de qualquer outro metal, é um fenómeno electroquímico, ou seja, em que há transferência de electrôes, exigindo portanto a presença de água, para receber os iōes formados. Assim, numa zona em que está a dar-se corrosão ocorrerá a reação:

$\mathrm{Fe} \rightarrow \mathrm{Fe}^{2+}+2 \mathrm{e}$

passando o ião para a solução e ficando o electrão no metal, que deste modo se carrega negativamente.

Para que a reacção continue a processar-se será necessário que no meio exista uma espécie capaz de se reduzir, isto é, captar os electrðes. Ora geralmente há duas espécies aptas a provocar esta redução, o ião $\mathrm{H}^{+}$e o oxigénio:

$2 \mathrm{H}^{+}+2 \mathrm{e} \rightarrow \mathrm{H}_{2}$ (em meio ácido)

$\mathrm{O}_{2}+2 \mathrm{H}_{2} \mathrm{O}+4 \mathrm{e} \rightarrow 4\left(\mathrm{OH}^{-}\right)(\mathrm{em}$ meio neutro ou alcalino)

Em condiçðes atmosféricas evidentemente que predomina a segunda reacção.

Estabelece-se assim à superficie do metal uma multiplicidade de micropilhas, cujos polos (cátodo e ânodo) podem variar de posição com o tempo, resultando então uma corrosão uniforme, ou mantê-la mais ou menos, e a corrosão é localizada, tipo que é sempre mais perigoso.

A formação de uma camada protectora, que amortece o prosseguimento da corrosão, deve-se à precipitação, na superficie do metal, de compostos provenientes da reacção do ião metálico com qualquer espécie existente no meio. Geralmente a reacção dá-se com o próprio $\mathrm{OH}^{-}$libertado, visto que os ânodos e cátodos estão muito próximos, podendo também formar-se outros compostos, em maior ou menor proporção, conforme a respectiva insolubilidade e quantidade da referida espécie. Tratando-se de corrosão atmosférica muitas vezes estes compostos são sais básicos.

Ora, no caso do ferro acontece que o hidróxido de possivel formação:

$\mathrm{Fe}^{2+}+2 \mathrm{H}^{-} \rightarrow \mathrm{Fe}(\mathrm{OH})_{2}$

é relativamente solúvel e precipita com certo afastamento da superfície metálica, originando produtos soltos e porosos que se mantêm permeáveis à água e ao ar. Deste modo a camada de produtos de corrosão não tem qualquer poder protector e a corrosão continua. Numa reacção posterior o oxigénio oxidará o $\mathrm{Fe}(\mathrm{OH})_{2}$ produzindo a ferrugem, mistura de óxidos mais ou menos hidratados, como por exemplo, $\mathrm{Fe}_{2} \mathrm{O}_{3}, \mathrm{nH}_{2} \mathrm{O}$.

Assim, a menos que se trate duma atmosfera extremamente seca como a que existe em Delhi, onde uma coluna de ferro datada do séc. IV permanece ainda agora em bom estado, não há amortecimento do fenómeno corrosivo.

Ora, para além de soltos e permeáveis, os produtos de corrosão do ferro ocupam um volume muito maior do que o do metal desaparecido, desenvolvendo portanto forças expansivas que provocam a rotura das pedras em que as peças de ferro ou aço estão introduzidas.

Foi o que se passou no caso citado da Acrópole de Atenas.

Mas já na Babilónia se usavam gatos de ferro e na primitiva Acrópole também a união das pedras se fazia com aço, quer no interior das colunas, quer nas ligaçठes das pedras das paredes, sem que se tenham produzido roturas... Simplesmente o aço estava revestido de chumbo, pois era este metal que assegurava a aderência à pedra, dada a sua maleabilidade. E o chumbo, como se disse, resiste bem à corrosão atmosférica.

$\mathrm{Na}$ restauração da Acrópole, a ligação entre o aço e as pedras processava-se muitas vezes por uma calda de cimento, ficando o metal nas condiçðes de uma armadura de betão, isto é, protegido contra a corrosão, porque num meio alcalino, como é o resultado da hidratação do cimento, o aço se encontra passivado. Porém, c estado de passivação perde-se quando, por exemplo, sє dá a carbonatação do hidróxido de cálcio libertado ne hidratação do cimento, pelo dióxido de carbono do ar acção tanto mais rápida quanto a permeabilidade de calda for maior. Também os poluentes industriais áci dos, como são os derivados do enxofre, têm acçãc análoga, reforçando portanto a do dióxido de carbono. Acresce que a proximidade do mar - caso da Acrópole - terá agravado o fenómeno, pois os cloretos destroem também, e muito activamente, a passivação. Além disso aumentam a condutividade do meio, o que favorece, como é óbvio, a velocidade dos fenómenos electroquímicos.

É pois necessário prever nas restauraçōes em que se usem gatos, chumbadouros ou outras peças de metal, que este seja resistente à corrosão, sugerindo-se as ligas de titânio, o aço inoxidável e o bronze por ordem decrescente, conforme a agressividade do ambiente e a preciosidade do monumento.

Foca-se também que a corrosão pode, destruindo c metal, pôr em perigo a segurança das estruturas de reforço dos monumentos restaurados, o que, não sendo uma causa de deterioração da pedra, é certamente uma causa de deterioração dos monumentos.

Deve pois cuidar-se para que as estruturas metálicas fiquem bem protegidas contra a corrosão. 